www.jmscr.igmpublication.org Impact Factor 5.244

Index Copernicus Value: 5.88 ISSN (e)-2347-176x ISSN (p) 2455-0450 crossref DOI: _http://dx.doi.org/10.18535/jmscr/v4i5.17

Journal Of Medical Science And Clinical Research

\title{
Induced To Differentiation and Morphogenesis of Pancreatic Islet Clusters: Effects on Glycated Fetal Bovine Serum
}

\author{
Authors \\ Sivalingam Murugan ${ }^{1}$, Ikuo Nishigaki ${ }^{2}$, Gowri Rangasamy Gunassekaran ${ }^{3}$, \\ Ganapathy Ekambaram ${ }^{4}$, Kalpana Deepa Priya Dorayappan ${ }^{5}$, Vishal Babu ${ }^{6}$ \\ Ameesh Madhusoodhanan Nair ${ }^{7}$ \\ ${ }^{1}$ Assistant Professor, ${ }^{7}$ Tutor, ${ }^{6}$ Associate professor, Govt. Medical College, Palakkad, Kerala, India \\ ${ }^{3}$ Post-Doctoral fellow, Kyungpook National University, South Korea \\ ${ }^{4}$ Assistant Project Scientist, California University, USA \\ ${ }^{5}$ Post-doctoral Researcher, Ohio State University, USA \\ ${ }^{2}$ NPO International Laboratory of Biochemistry, 1-166 Uchide, Nakagawa-ku, Nagoya 454-0926, Japan \\ *Corresponding Author \\ Ikuo Nishigaki \\ Director, NPO International Laboratory of Biochemistry, 1-166 Uchide, Nakagawa-ku, \\ Nagoya 454-0926, Japan \\ Email: murugans80@gmail.com
}

\begin{abstract}
Mouse embryonic stem cells (MESCs) are potency to differentiate into mature pancreatic islet cells and using for tissue repair treatment. Advanced glycation end-products (AGEs) are accrual of long lived proteins of various tissues and have been implicated in chronic complications in diabetes mellitus, but the pathogenic role of AGEs on pancreatic islet cells is remains unclear. Stem cell differentiation is carried out based on standard protocol followed in the laboratory. In results the differentiated stem cells shows extensive self-renewal capacity and grow in highly viable for long term in the culture media, had remarkable size, formed aggregates, which built tissue like structures and closer examination by light microscopy analysis revealed islet cell like morphology. Administration of GFBS +iron on induced pancreatic islet cells is observed induce charity of cells. Conclusion this findings demonstrate that AGEs directly cause insulin secretory defects and toxicity, most likely by impairing pancreatic cell functions, which may contribute to the development of diabetes. This approach offers a promising an ample supply of insulin producing cells for cell transplantation therapy and maintains the complication factors in diabetic mellitus, suggesting that further improvement is needed.
\end{abstract}

Keywords: Embryonic stem cell, insulin producing cell, diabetes, Glycated bovine albumin

\section{Introduction}

Diabetes mellitus (DM) is a multifactorial disease characterized by hyperglycemia and glucose intolerance due to insulin deficiency, one major contributing factor to diabetic complications ${ }^{[1]}$.
Every year increasing mortality, report said that around 350 million cases and 4.9 million people die from diabetes ${ }^{[1,2]}$. This indicates that the diagnostic and therapeutic possibilities are still limited at the moment. So, to prevent diabetic 
complications, an early diagnosis is very important.

Stem cells are self-renewing elements that can generate many specialized cell types function in the body. Embryonic stem (ES) cells have the capacity to proliferate and differentiate into any cells of the body. Alike stem cells could provide a potentially unlimited source of differentiated cells for the treatment of many diseases and aging ${ }^{[3]}$. Perhaps the most important application is that immunologically matched pluripotent cells are useful tools for the study of disease states and for cell based therapies ${ }^{[4]}$. However, still many questions about stem cell differentiation and therapy are remain. Example, previously one study showed that the embryonic stem cells can be efficiently induced to differentiate into insulin producing cells can self-assemble to form functional pancreatic islet like structures ${ }^{[5]}$. This results suggest that ES cells will provide a powerful tool to study pancreatic development, function and treat the disease. In view, although the understanding basic level mechanism of formation of cells or tissues and defect by complicated substances produced in the body are still remains. So, the aim of the study is to explore the morphology changes of invitro differentiation of mouse embryonic stem cells (MESC) into functional pancreatic islet like cluster cells and to test efficacy of glycated albumin. The focuses on the role that advanced glycation plays in the initiation and progression of diabetic complications, which can ameliorate the toxic effects of these products and speculate about novel therapeutic interventions. It has been reported as stepwise protocol, by which they obtained similar to insulin producing pancreatic islet cells ${ }^{[6]}$. Similarly, the exciting prospect of generating pluripotent cells from any source warrants a deep understanding of the reprogramming process. This will lead to improvements in efficiency and methods of generation and ensure the safety of the cells for therapeutic use.

Albumin is one of longest proteins of plasma ${ }^{[7]}$. Glycated albumin is a potential disease marker in in vitro and in vivo models. Glycation is nonenzymatic process in protein with sugar molecules, which are the factor in worsening of many degenerative diseases ${ }^{[8]}$. Advanced Glycation End Products (AGE), a group of modified proteins with damaging potential, is one contributing factor in diabetic mellitus ${ }^{[8]}$. In links one report revealed that AGEs is involved in the stimulate several upstream signaling pathways [9,10,11]. Based on the recent and reviews, we examined the possible effects of glycated product on induced pancreatic islet cells using GFBS. Iron is one of the important essential minerals, and its abnormal homeostasis such as deficiency or overload is associated with the pathogenesis of various chronic diseases including diabetes ${ }^{[12,13]}$. Although recent reviews have discussed the associations of iron overload with the risk of insulin resistance and type 2 diabetes ${ }^{[14,15]}$. Increasing evidence has indicated that iron overload not only increases risks of insulin resistance and diabetes, but also causes cardiovascular diseases in diabetic and nondiabetic subjects ${ }^{[2]}$. New insights are needed to understand the possible mechanisms by iron overload may cause the onset of diabetes and diabetic complications.

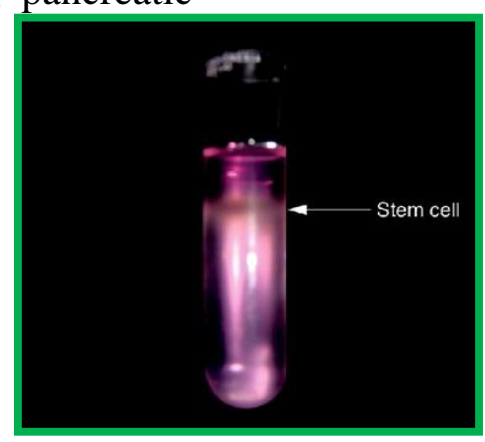

Fig.1 Separation of stem cells ${ }^{[16]}$ (Courtesy: Ikuo Nishigaki et al., 2011) 

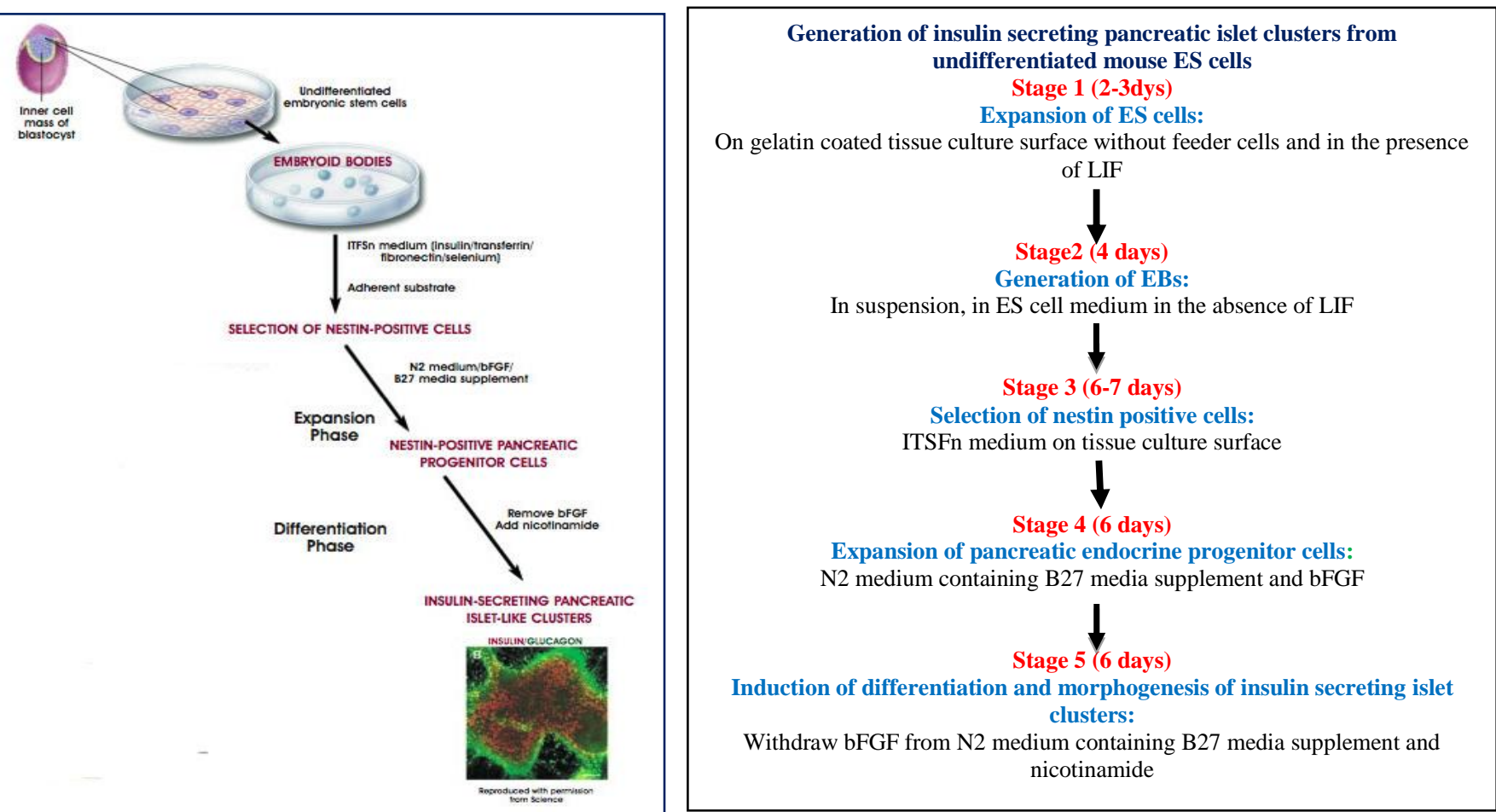

Fig:2 a, b Model protocol for differentiation of pancreatic islet like cluster ${ }^{[4]}$ (Courtesy: Nadya Lumelsky et al., 2001)

\section{Materials and methods}

Stem Cell: The embryonic stem cell line used for this project was CMTI-1 (Millipore Co., Billerica, MA, U.S.A.). Briefly ESCs were maintained on precoated gelatin $\mathrm{T}$ flasks (Nunc, Roskilde, Denmark) with or without mitotically inactivated feeder layer of primary culture of mouse embryonic fibroblast (PMEF-P3 cells; Millipore Co.) in ESC medium containing knockout Dulbecco's modified Eagle medium (KO-DMEM; Invitrogen, Paisley, U.K), supplemented with 100 $\mathrm{U} / \mathrm{ml}$ penicillin, $100 \mu \mathrm{g} / \mathrm{ml}$ streptomycin, $100 \mu \mathrm{M}$ $\beta$-mercaptoethanol, $2 \mathrm{mM}$ L-glutamine, $1 \%$ nonessential amino acids, 15\% FBS, and $1000 \mathrm{U} / \mathrm{ml}$ leukemia inhibitory factor (LIF; Chemicon, Temecula, CA, U.S.A.). Cultures were grown in $5 \% \mathrm{CO}_{2}$ at $37^{\circ} \mathrm{C}$ and were checked frequently and the medium was changed every two days. All chemicals used were of analytical grade and water was purified by using a Millipore Milli Q system (Millipore Co.).

Glycation of Fetal Bovine Serum (GFBS): For the glycation of FBS, $100 \mathrm{ml}$ of FBS was incubated with $50 \mathrm{mM}$ glucose at $37^{\circ} \mathrm{C}$ for 50 days under sterile conditions. After the incubation, the mixture was dialyzed against $67 \mathrm{mM}$ phosphate buffer ( $\mathrm{pH} 7.4$ ) at $4 \circ \mathrm{C}$. The dialysate was used as GFBS after having been concentrated by using an Aquacide II (Calbiochem Novabiochem Corp., La Jolla, CA, U.S.A.). Pentosidine content was evaluated as a measure of glycations. The concentration of pentosidine in GFBS was 0.03 $\mu \mathrm{g} / \mathrm{ml}$ in experimental media. The extent of glycation of GFBS was assayed with a commercial kit (Nippon Roche, Tokyo, Japan) and expressed as the FV. The FV of the prepared GFBS was $12 \mathrm{mM}$, whereas that of the original FBS was $0.16 \mathrm{mM}$.

\section{Differentiation method of Mouse ES Cells into} Insulin producing Cells

\section{Stem cells were differentiated without feeder cells:}

Stage 1: mouse ES cells were cultured on a gelatin coated culture surface without a feeder layer in ESC medium for 4 days to maintain the cells in the undifferentiated state. Stage 2: Stem cell separation on Histopaque density gradient: ES cells grown on the feeder cell layers were collected by centrifugation after trypsin treatment, resuspended in $4 \mathrm{ml}$ of ES medium, and subjected 
to Histopaque density-gradient separation [17] (Fig.1). Stage 3: separated ES cells were transferred to flasks coated with Poly-L-ornithine and laminin peptide. To select nestin-positive cells, ES cells were maintained for 7 days in culture flasks containing serum-free medium supplemented with ITS solution having final concentrations of $10 \mathrm{mg} / \mathrm{l}$ insulin, $56 \mathrm{mg} / \mathrm{l}$ transferrin, $6.7 \mathrm{mg} / \mathrm{l}$ selenium, and $5 \mathrm{mg} / \mathrm{l}$ fibronectin. Stage 4: Nestin-positive cells were cultured for 4 days in the presence of Activin B (10 ng/ml, GIBCO/BRL) in serum-free medium to expand the pancreatic progenitor cells. Stage 5: In order to induce the differentiation of the cells into insulin-producing cells, $10 \mathrm{mM}$ nicotinamide (Sigma) was added to the cultures ${ }^{[4]}$. The differentiation of stem cells into insulin producing cells was determined by stimulating the cells for insulin production using glucose and by subjecting the cells for insulin release test. As our interest is strongly set on the effect of glycated bovine serum and/with iron on stem cell, our data was collected only using stem cells differentiated by method $2^{[16]}$.

\section{Results}

\section{Morphological changes of ESC differentiation}

The differentiated cells morphology changes were investigated under converted microscope for assess the function. Under inversed microscope, differentiated ESCs were typical spindle-like cells changed rapidly into round or oval types with confluence of many colonies formed and abundant in endocrinal granules (Fig.3a, b) when compared to undifferentiated state of adherent spindle and fibrocyte- like. Some cells changed into neuronlike cells with typical processes (fig.3c). Nestin was regarded as an important premarker for islet cell differentiation, and its expression was observed under microscope. Nestin could be observed obviously shows nestin positivity in predifferentiated spindle-like cells (Figure 3.d, e), while no nestin positivity in differentiated isletlike cells. Many neurons like structure was formed at the end of stage 4 medium containing B27 media supplement and bFGF may be due to growth factor action (fig.3e). Differentiated pancreatic islet cells were form compact colonies of cobblestone-like cells and well established monolayers and complete reorganization into a three-dimensional islet like structure (fig3.f). At the end of final stage, after differentiation of the cells gradually formed clusters and floated in the medium. It seems therefore that the induction of an increase in the number of insulin producing cells may be one of the several protocols. On administration of GFBS + iron on islet cells we observed charring of cluster might be involved in the severity of cells injury when compared with glucose treatment (fig.3g-h).

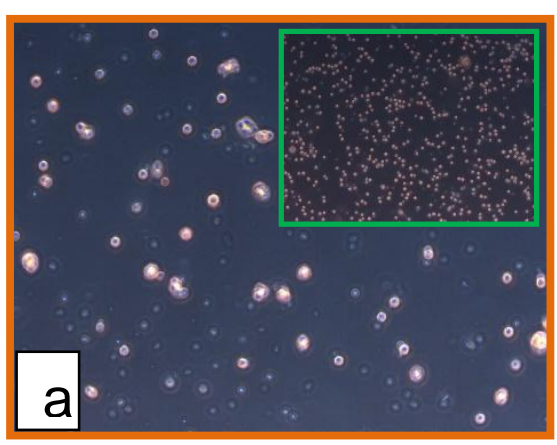

Stem cells in undifferentiated state

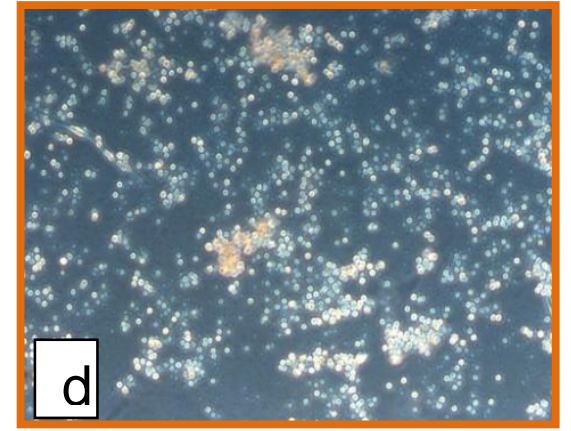

Nestin positive cells 


\section{JMSCR Vol||04||Issue||05||Page 10490-10497||May}

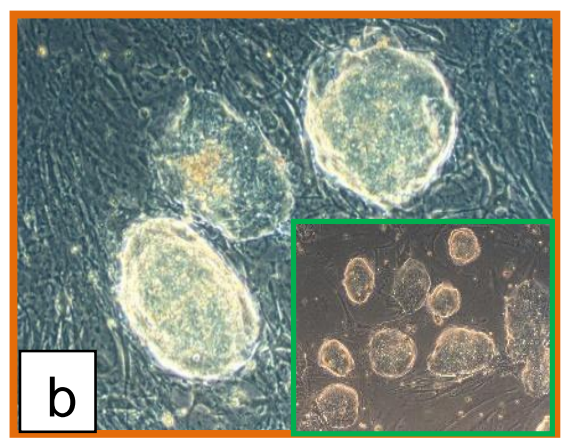

Embryoid Bodies Formation

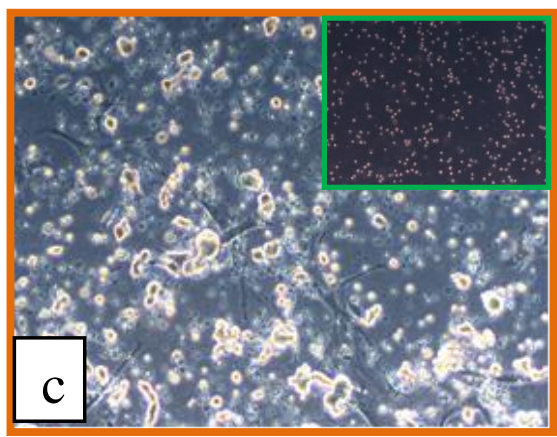

After Histopaque Cells grow in PLO coated flask

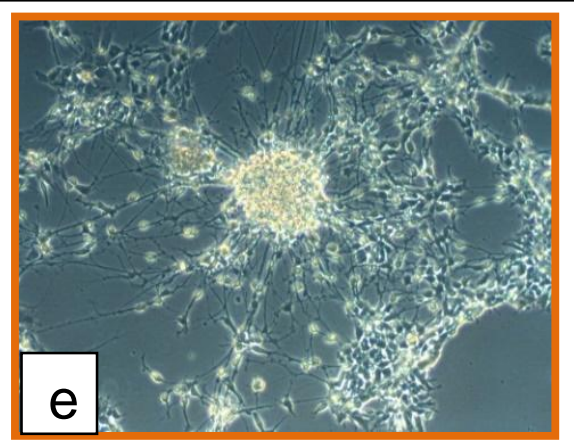

Nestin positive pancreatic progenitor cells

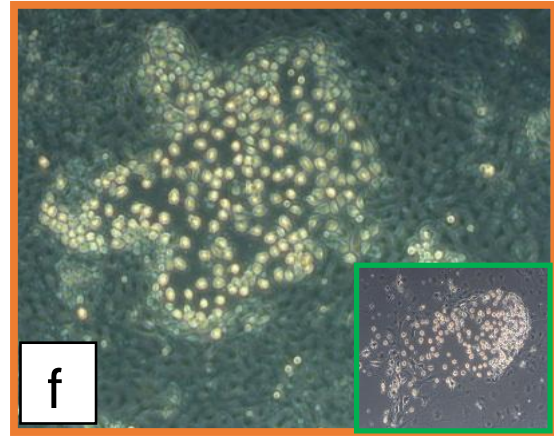

Pancreatic islet like cluster
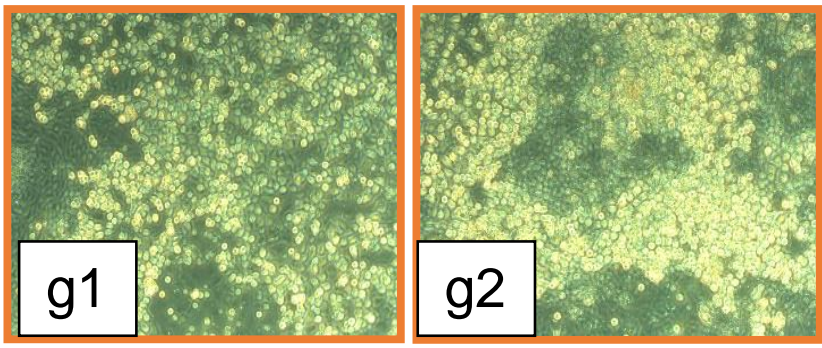

glucose treatment

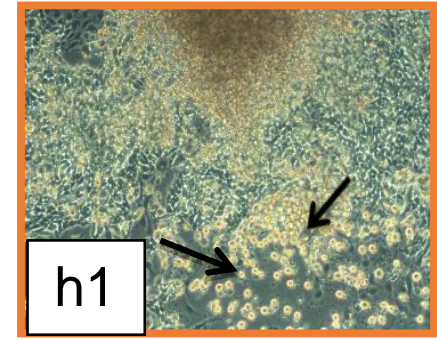

GFBS treatment

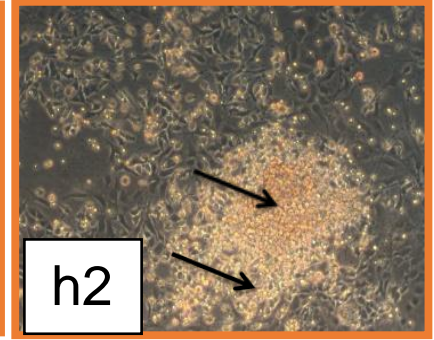

GFBS+ iron

Fig:3. Differentiation of pancreatic islet cells from embryonic stem cells and effects on glycated protein

\section{Discussion}

Embryonic stem cells (ESC) are pluripotent derived from the earliest stages of embryonic development. It has been previously demonstrated that ES cells can coordinately differentiate into multiple cell types found throughout the body ${ }^{[18,19]}$. Interestingly, previous one report shown as to spontaneously reassociate and aggregates with three dimensional architectures as typical of native islets cells ${ }^{[20]}$. It is important to note that insulin production and form clusters similar of normal islets. Because, there was an argument that Islet like cells differentiated from ESC were falsely insulin positive from insulin uptake ${ }^{[21]}$. Besides, many reports proven that insulin positive cells form aggregates morphologically similar to normal pancreatic islets ${ }^{[4]}$. To clarify that, we simulated to conducted experiment, alike our results obtained that ES cell generates populations that self-assemble into structures resembling pancreatic islets both topologically and functionally (Fig.3f). Once homing of these cells to pancreatic islets has occurred, local cell to cell interaction as well as paracrine factors may initiate differentiation.

Morphological changes of ESC differentiation were observed under inversed microscope, undifferentiated state stem cells were typical of adherent spindle and fibrocyte like structure but in differentiation these spindle like cells changed rapidly into round or oval types with confluence of embryoid bodies formed (fig.3a, b). 
Microscopic analysis of the embryonic bodies (EB) margin revealed loose and floating cell aggregates, from which single cells were released (Fig.3b). Depending on the size of the EB, cells were produced per day. These generated cells accumulated in the culture media and were carefully analyzed. Some cells changed into neuron like cells with typical processes (fig.3e). Nestin is a marker of precursors of pancreatic islet cells ${ }^{[22,4]}$. $\quad \beta$-mercaptoethanol is a neurocyte inducer involved in increased the potency of nicotinamide to differentiate islets cells. So in our study, its similar observed that nestin positive ESCs could differentiate into prepancreatic islet cells. Its formed well established monolayers of pancreatic islet cells and complete reorganization into a three-dimensional islet like structure. These cells were morphologically similar to pancreatic islet cells (fig.3f). They proliferated also in suspension and had properties completely different from the started adherent growing cultures (Fig f). One study showed that high glucose is a potent inducer for pancreatic islet differentiation and nicotinamide was used to preserve islet viability and function ${ }^{[23]}$. In our primary experiment shows high glucose alone could not effectively induce ESC to differentiate into islet like cells. After nicotinamide was added, they could effectively transform ESCs into aggregated to many colonies of pancreatic isletlike cells (fig.3f). This may imply that nicotinamide could be an effective inducer, or transforming into other cell types. we did not test the insulin secretion based on the number of cells, but the increased insulin in supernatant might be mainly from increased insulin excretion by isletlike cells.

Several studies, suggesting that formation of advanced glycation end products (AGEs), is one of the contributing factor and even predictors for diabetic complications ${ }^{[8]}$. Further evidence indicates that AGEs affect insulin secretion by beta cell death ${ }^{[24-27]}$. In order to curiosity to find out this effects on differentiated pancreatic stem cells, we administered GFBS+ iron for one week. Iron is a very important essential mineral contribute certain pathogenic outcomes in the body. Increased level iron was significantly associated with an increased risk of insulin resistance and also increases the risk of cardiovascular disease in diabetic patients ${ }^{[28-30]}$. Similarly, our result also obtained that affects insulin secretion and cell death, it may due to toxicity of glycated albumin. From this observed evidence we concluded that glycated fetal bovine serum induce toxicity to differentiated pancreatic islet cells. Although more systemic clinic observation remains needed for clarifying the outcomes of various iron chelators for diabetes and its complications.

\section{Conclusion}

The islet like functional cells can be differentiated from mouse embryonic stem cells, which may be a new approach for cell based therapy of diabetic mellitus. The current article reports a potential generate insulin producing islet cells differentiation from embryonic stem cells. The AGEs is play pathological role in the development and progression of diabetic diseases, which were in insulin resistance, $\beta$ cell failure and diabetic complications It is also very interesting that the observation of insulin positive cells are lower in the GFBS + iron treated culture flasks than that of the controls. The reason for this discrepancy may be attributed to the fact that some islet cells may have been completely destroyed with no possibility of recovery, whereas the others were partially damaged. In this respect, glycated albumin may induce toxicity by the destruction of the insulin positive cells, may depends upon the use of different AGE precursors and different concentration, mechanism is unknown. It needs further research for fully understood of AGE for therapeutic approaches against the pathological events in diabetes and associated diseases.

\section{References}

1. International Diabetes Federation (IDF). IDF Diabetes Atlas Update Poster, 6th ed.; International Diabetes Federation: Brussels, Belgium, 2014. 
2. Morrish, N. Wang, S.L. Stevens, L. Fuller, J. Keen, H. Mortality and causes of death in the who multinational study of vascular disease in diabetes. Diabetologia, 2001, 44: 14-21.

3. Johnson, B.V.N. Shindo, P.D. Rathjen, J. Rathjen, J. Keough R.A. Understanding pluripotency- how embryonic stem cells keep their options open. Molecular Human Reproduction, 2008,14(9):513-520.

4. Qiuju Liu, Liang Sun, Yi Tan, Guanjun Wang, $\mathrm{Xu}$ Lin, and Lu Cai. Role of Iron Deficiency and Overload in the Pathogenesis of Diabetes and Diabetic Complications. Current Medicinal Chemistry, 2009, 16: 113-129.

5. Wei, J. Yan Shi, Dongxin Zhao, Song Chen, Jun Yong, Jing Zhang, Tingting Qing, Xiaoning Sun, Peng Zhang, Mingxiao Ding, Dongsheng Li, Hongkui Deng. In vitro derivation of functional insulin producing cells from human embryonic stem cells. Cell Research, 2007, 17: 333-344.

6. Nadya Lumelsky, Olivier Blondel, Pascal Laeng, Ivan Velasco, Rea Ravin, Ron McKay. Differentiation of Embryonic Stem Cells to Insulin-Secreting Structures Similar to Pancreatic Islets. Science, 2001, 292(18): 1389-1394.

7. Rondeau, P. Navara, G. Militello, V. Bourdon, E. On the aggregation of albumin: Influences of the protein glycation. In protein aggregation. Edited by Douglas A, Stein Nova Science publishers, in 2010.

8. Kerstin Nowotny, Tobias Jung, Annika Höhn, Daniela Weber and Tilman Grune. Advanced Glycation End Products and Oxidative Stress in Type 2 Diabetes Mellitus. Biomolecules, 2015, 5: 194-222.

9. Cellek, S. Point of NO return for intrinsic nerves in diabetes: a new insight into diabetic complications. Curr. Pharm. Des., 2004, 10: 3683-3695.
10. Denis, U. Lecomte, M. Paget, C. Ruggiero, D. Wiernsperger, N. Lagarde, M. Advanced glycation end-products induce apoptosis of bovine retinal pericytes in culture: involvement of diacylglycerol/ ceramide production and oxidative stress induction. Free Radic. Biol. Med.,2002, 33: 236-247.

11. Ramasamy, R. Vannucci, S.J. Yan, S.S. Herold, K. Yan, S.F. Schmidt, A.M. Advanced glycation end products and RAGE: a common thread in aging, diabetes, neurodegeneration, and inflammation. Glycobiology, 2005, 15:1628.

12. Wilson, J.G. Lindquist, J.H. Grambow, S.C. Crook, E.D. Maher, J.F. Potential role of increased iron stores in diabetes. Am. J. Med. Sci., 2003, 325: 332-9.

13. Beutler, E. Hoffbrand, A.V. Cook, J.D. Iron deficiency and overload. Hematology. Am. Soc. Hematol. Educ. Program, 2003, 40-61.

14. Swaminathan, S. Fonseca, V.A. Alam, M.G. Shah, S.V. The role of iron in diabetes and its complications. Diabetes Care, 2007, 30: 1926-33.

15. Rajpathak, S.N. Crandall, J.P. Wylie Rosett, J. Kabat, G.C. Rohan, T.E. Hu, F.B. The role of iron in type 2 diabetes in humans. Biochim. Biophys. Acta, 2009, 1790(7):671-681.

16. Ikuo Nishigaki, Gowri Rangasamy Gunassekaran, Panjan Nagappan Venkatesan, Mandupal haco Sabu, Sabu Priya, Peramaiyan Rajendran, Dhanapal Sakthisekaran and Yutaka Nishigaki. Stimulatory Role of Glycated Fetal Bovine Serum Along with Iron on in vitro Production of Insulin by Differentiated Mouse Embryonic Stem Cells. Journal of Health Science, 2011, 57(4): 356-361.

17. Zhixin, L. I. Matthew, R. Barron, J. L. and Ming. Rapid single-step separation of pluripotent mouse embryonic stem cells 
from mouse feeder fibroblasts. Stem Cells Dev., 2008, 17: 383-387.

18. Yamashita J, Hiroshi Itoh, Masanori Hirashima, Minetaro Ogawa, Satomi Nishikawa, Takami Yurugi, Makoto Naito, Kazuwa Nakao and Shin-Ichi Nishikawa. Flk1-positive cells derived from embryonic stem cells serve as vascular progenitors. Nature, 2000, 408: 92-96

19. Lee, S.H. Lumelsky, N. Studer, L. Auerbach, J.M. McKay, R. D. Efficient generation of midbrain and hindbrain neurons from mouse embryonic stem cells. Nat Biotechnol., 2000,18(6):675-9.

20. Halban, P. A. Powers, S. L. George, K.L. Bonner Weir, S. Spontaneous reassociation of dispersed adult rat pancreatic islet cells into aggregates with three-dimensional architecture typical of native islets. , 1987, 36(7):783-90.

21. Rajagopal, J. Anderson, W. J. Kume, S. Martinez, O. I. Melton, D. A. Insulin staining of ES cell progeny from insulin uptake. Science, 2003, 299(5605):363.

22. Zulewski, H. Abraham, E.J. Gerlach, M.J. Daniel, P.B. Moritz, W. Muller, B. Vallejo, M. Thomas, M.K. Habener, J.F. Multipotential nestin-positive stem cells isolated from adult pancreatic islets differentiate ex vivo into pancreatic endocrine, exocrine and hepatic phenotypes. Diabetes, 2001, 50: 521-533.

23. Kolb, H. Burkart, V. Nicotinamide in type 1 diabetes: Mechanism of action revisited. Diabetes Care, 1999, 22(2):16-20.

24. Luciano Viviani, G. Puddu, A. Sacchi, G. Garuti, A. Storace, D. Durante, A. Monacelli, F. Odetti, P. Glycated fetal calf serum affects the viability of an insulin secreting cell line in vitro. Metabolism, 2008, 57: 163-169.
25. Zhao, Z. Zhao, C. Zhang, X.H. Zheng, F. Cai, W. Vlassara, H. Ma, Z.A. Advanced glycation end products inhibit glucosestimulated insulin secretion through nitric oxide-dependent inhibition of cytochrome $\mathrm{C}$ oxidase and adenosine triphosphate synthesis. Endocrinology, 2009, 150:25692576.

26. Lin, N. Zhang, H. Su, Q. Advanced glycation end-products induce injury to pancreatic beta cells through oxidative stress. Diabetes Metab., 2012, 38: 250257.

27. Zhu, Y. Shu, T. Lin, Y. Wang, H; Yang, J. Shi, Y. Han, X. Inhibition of the receptor for advanced glycation end products (RAGE) protects pancreatic beta cells. Biochem. Biophys. Res. Commun., 2011, 404: 159-165.

28. Rajpathak, S. Ma, J. Manson, J. Willett, W.C. Hu, F.B. Iron intake and the risk of type 2 diabetes in women: a prospective cohort study. Diabetes Care, 2006, 29: 1370-6.

29. Wrede, C.E. Buettner, R. Bollheimer, L.C. Scholmerich, J. Palitzsch, K.D. Hellerbrand, C. Association between serum ferritin and the insulin resistance syndrome in a representative population. Eur. J. Endocrinol., 2006, 154: 333-40.

30. Ana Flavia, S. Sampaio, Maisa Silva, Waleska, C. Dornas Daniela, C. Costa, Marcelo, E. Silva, Rinaldo, C. dos Santos, Wanderson, G. de Lima, Maria Lucia Pedrosa. Iron toxicity mediated by oxidative stress enhances tissue damage in an animal model of diabetes. Biometals, 2014, 27(2):349-361. 